\title{
Langerhans cell histiocytosis
}

\author{
Disciplina de Hematologia e Hemoterapia, Disciplina de Clínica Médica, Disciplina de Anatomia Patológica, \\ Disciplina de Dermatologia, Disciplina de Pneumologia - Escola Paulista de Medicina, \\ Universidade Federal de São Paulo - São Paulo, Brazil.
}

The authors present a rare case of Langerhans cell histiocytosis in a 31 year old female patient with vulvar, peri-anal and oral lesions, diabetes insipidus, pulmonary skin and bone infiltrations. Skin biopsy immunohistochemistry presented positive S100 protein and vimentine, but the diagnosis was done with the demonstration of Birbeck granules with eletronic mucroscopy. The treatment was based on systemical chemotherapy although vulvar lesion has a bad response to chemotherapy.

UNITERMS: Histiocytosis X, Langerhans cell. Diabetes insipidus.

\section{INTRODUCTION}

$\mathrm{T}$ he authors present a rare case of Langerhans cell histiocytosis $(\mathrm{LCH})$ with vulvar, perianal and oral lesions, pulmonary and diabetes insipidus(DI), skin and bone infiltrations.

\section{CASE REPORT}

A 31-year old white woman was admitted to the Hospital S. Paulo in April, 1996, due to an ulcerated lesion

\footnotetext{
Address for correspondence:

Maria de Lourdes L. F. Chauffaille

Rua Botucatu, 740 - $3^{\circ}$ andar

São Paulo/SP - Brasil - CEP 04023-900
}

in the vulva that had appeared 1 year previously. She also complained of cutaneous nodes in the right shoulder and forearm, gengivitis, loosening of the teeth, halitosis, otorrhea, polydipsia, amenorrhea, galactorrhea and a weight gain of $24 \mathrm{~kg}$ in the three previous years, as well as a spontaneous pneumothorax 10 years earlier. She was obese, with a $3 \mathrm{~cm}$ brownish-red papular lesion on the right shoulder and another of $1 \mathrm{~cm}$ on the forearm; erythematous plaque in the roof of the mouth, with superior teeth extrusion and loosening. The liver was 5 $\mathrm{cm}$ from the LCM and there was edema of the labia majoris and ulcerated vulvar lesion with a granulomatous aspect; and a perianal lesion with the same characteristics. Laboratory exams: $\mathrm{Hb}=13.7 \mathrm{~g} / \mathrm{dl} ; \mathrm{WBC}=6.700 / \mathrm{mm} 3$ (stab $1 \%$, segmented $56 \%$, eosinophils $5 \%$, basophils $1 \%$, lymphocytes $30 \%$, monocytes $7 \%$ ); Platelets $=230.000 /$ $\mathrm{mm}^{3} ; \mathrm{SGOT}=54(13)$, SGPT $=60(14)$, alkaline phosphatase $=340(250), \mathrm{LDH}=424(450)$, uric acid=7.8 (6.0); the pulmonary function had a mixed ventilatory abnormality and predominance of a light restrictive pattern; transbronchial biopsy presented unspecific infiltrate; water deprivation test consistent with DI and megatest consistent 


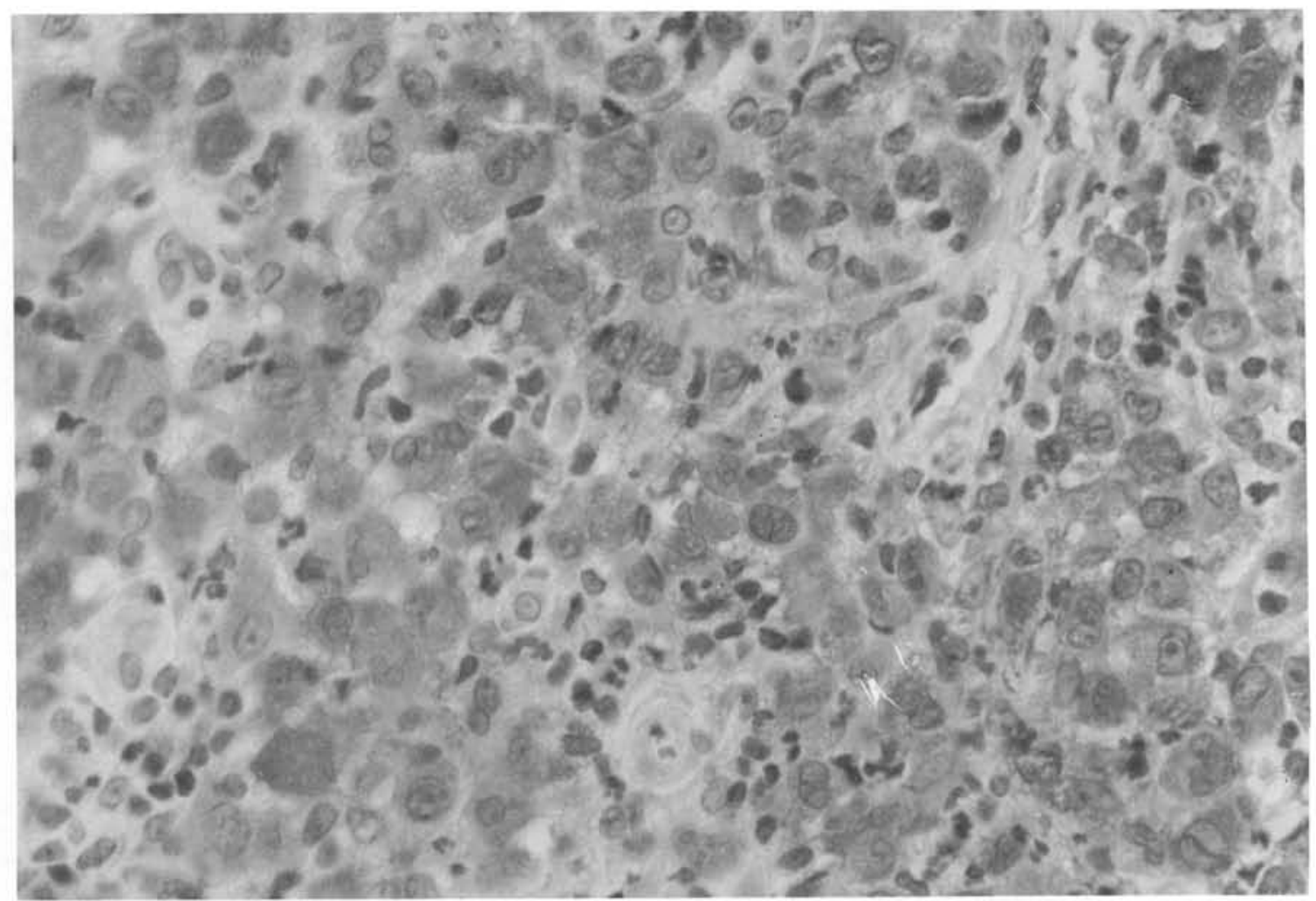

Figure 1 - Immunohistochemistry showing positive S100 protein.

with panhypopituitarism; chest radiography showed bilateral interstitial infiltrate with mediastinum enlargement; bone scintillography had anomalous hyperconcentration of radioindicator in the distal third of the bilateral femur, in the focal left paranasal area and in the jaw; computerized tomography (CT) with interstitial micronodular infiltration, cystic areas in pulmonar parenchyma and interlobular fissure in the rosary; skull magnetic nuclear resonance with a tumor in the infundibulo-hypothalamic area; abdominal scan with hepatomegaly and signs of moderate hepatic steatosis. Skin and vulvar lesion biopsies showed Langerhans cell histiocytosis with positive $\mathrm{S} 100$ protein, vimentine and HAM56, and negative LCA, HMB45, Pan B and Pan T antigens. Electron microscopy showed the presence of Birbeck granules.

\section{DISCUSSION}

Histiocytoses are disorders characterized by the proliferation of cells from the monocyte-phagocytic series.
There is a great biological diversity from a benign and indolent pattern to a malignant and fulminant one. It is more frequent in children with an average age of 2 or 3 years old ${ }^{(1)}$. Its incidence is estimated as 0.2 to 0.5 cases per 100,000 children per year in the USA. In adults, the incidence is unknown.

Its etiology is unknown but it is thought it could be a proliferative disorder in response to an antigenic stimulus of infectious, genetic abnormality, deregulated immune response, or even clonal origin.

Hand-Schüller-Christian, Letterer-Siwe and eosinophilic granuloma were the first clinical descriptions. Later on, they were named Histiocytosis X, where X stood for etiology unknown. In 1985 the International Group of Pathologists and Clinicians recommended a new classification that was published by the Writing Group of the Histiocyte Society (WGHS) dividing them into: Langerhans cell histiocytosis (LCH), non-Langerhans cell histiocytosis (NLCH) and malignant histiocytosis. This classification has the advantage of recognizing the pathognomonic cell.

Clinical presentation may be localized or systematic, invading skin, lungs and bones in adults, and bone marrow and lymphonodes in children. 


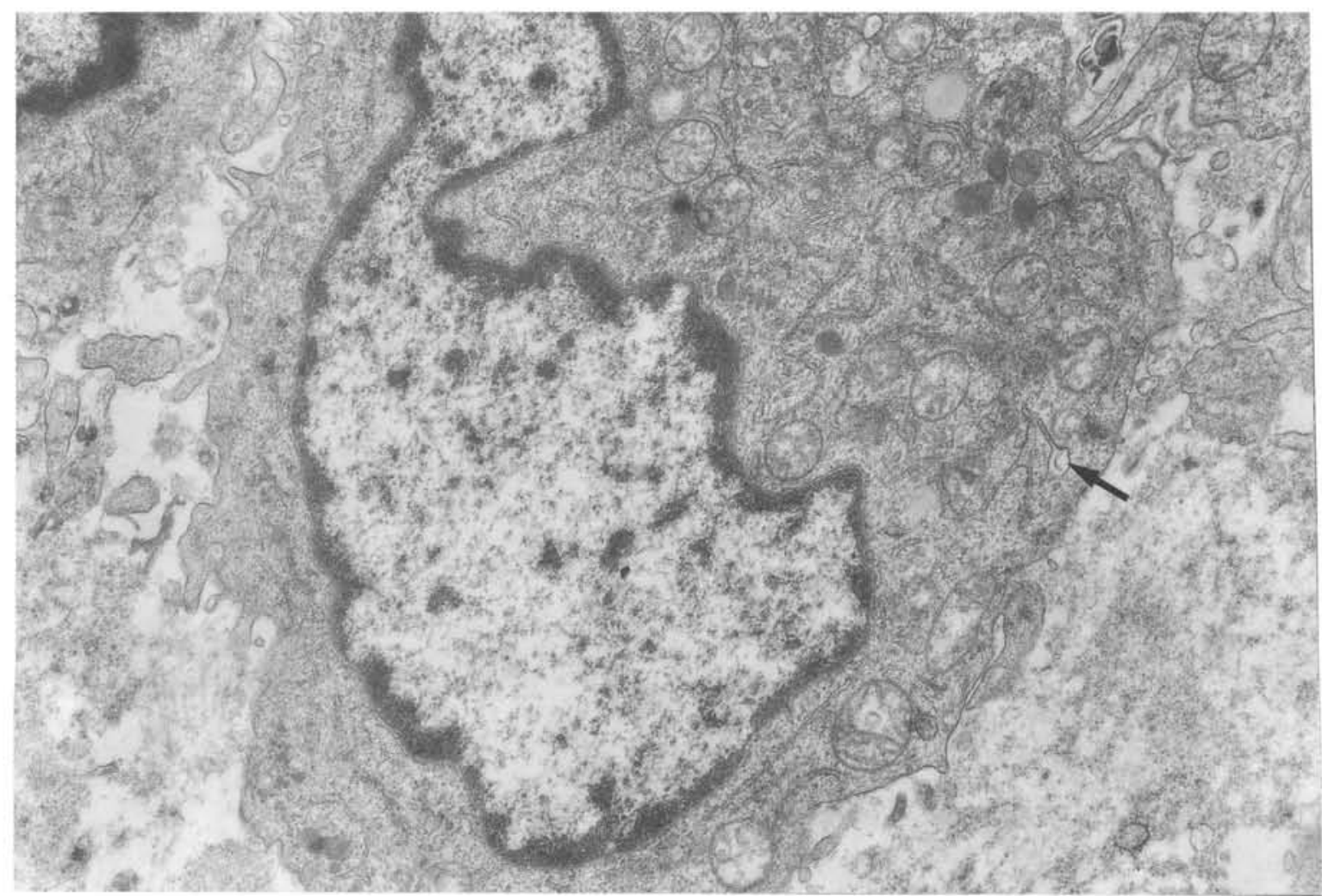

Figure 2 - Electron microscopy (400x): arrow showing the Birbeck granule.

Skin attack may be the only manifestation of the disease and may present spontaneous remission, or it may form part of the involvement of other organs with a worse prognosis. These lesions may precede systematic manifestations by one year or more. They occur in 30\% to $40 \%$ of the cases and are very heterogeneous. In the axillae, inguinal, perianal, neck and retroauricular areas, papules and subcutaneous nodes may ulcerate leading to lesions that are difficult to heal despite treatment. Genital ulcers are more frequent in adults. Localized or disseminated lesions occur in oral mucosa with plaques that tend to ulcerate leading to loss of teeth. These evident dermal-mucosal presentations were well documented in this case.

Lung involvement in $\mathrm{LCH}$ may be seen isolated or not ${ }^{(2)}$. In almost $20 \%$ of cases, spontaneous pneumothorax is the first manifestation of the disease. Radiologically, there are diffuse, reticulo-nodular opacities, over multiple cystic images mainly in the upper and mid-lung zones. The chest computerized tomography scan is superior to X-ray in detecting these abnormalities as was demonstrated here, since the "honey comb" abnormalities could be seen. Pulmonary function tests generally show a mixed pattern with lower diffusion capacity and hypoxemia that get worse with exercise (2).

Bone lesion, focal or disseminated, is lytic and may be curable with curettage, although it can reappear. Gingival infiltration with bone absorption leading to tooth floating is an adult feature of the disease.

Vulvar presentations are rare, but in adults it is more frequent with around 40 cases related in the literature. Considering the time of evolution for vulvar lesion presentation, the patients can be classified into 4 groups: genital tract only; lesions subsequently involving multiple organs; oral or skin lesions followed by involvement of the genital tract; and DI followed by involvement of multiple organs and genital lesions. The third case is apparently the most frequent ${ }^{(3)}$.

The diagnosis was made by lesion biopsy. Histochemistry was positive for S-100, CD1a, HLA$\mathrm{Dr}$ and vimentine, which are generally negative in $\mathrm{NLCH}$. The WGHS considers the presence of Birbeck granules or CDla positivity as fundamental criteria for 
the diagnosis. In the present case, the definitive diagnosis was made by demonstrating Birbeck granules with electron microscopy. Usually, histological aspects do not relate to the extension and agressiveness of the disease and in the initial phase the Langerhans cells and histiocytes may be seen in greater numbers.

It is important to know if the disease is localized or disseminated, since the involvement of more than one organ requires systematic therapy. The treatment in adults is based in polychemotherapy with etoposide, vinca alkaloids and glucocorticoid. Poor prognosis factors are advanced age, disease extent and functional organ abnormalities ${ }^{(4)}$. Relapses are common. Vulvar lesions do not improve with systematic chemotherapy needing local intervention. Radiotherapy, PUVA and intralesion glucocorticoid are also used. This patient received two cycles of etoposide $\left(100 \mathrm{mg} / \mathrm{m}^{2} /\right.$ day $/ 3$ days $)$ and vincristine $(2 \mathrm{mg} /$ day) every 30 days, without improvement. She was submitted to partial vulvectomy and is at present receiving vinblastine $10 \mathrm{mg} /$ week $/ 4$ months.

\section{RESUMO}

Os autores apresentam um caso raro de histiocitose de célula de Langerhans com apresentação lentamente progressiva, lesão vulvar, peri-anal e oral, diabete insipidus, infiltraçāo pulmonar, dérmica e óssea em paciente de 31 anos. A imunohistoquímica da biopsia de pele foi: proteína S-100 e vimentina positivas, porém o diagnóstico definitivo foi feito pela demonstração de grânulos de Birbeck à microscopia eletrônica. $O$ tratamento baseia-se em quimioterapia sistêmica e a lesão vulvar tem má resposta à quimioterapia.

\section{REFERENCES}

1. Trochtenberg DS, Dessypris EN. Case Report: reversible hepatomegaly and diabetes mellitus in an adult with disseminated histiocytosis X. Am J Med Sci 1990; 299(3):179-184.
2. Soler P, Kambouchner M, Valyere D, Hance AJ. Pulmonary Langerhans cell granulomatosis (histiocytosis X). Annu Rev Med 1992;43:105-115.

3. Axiotis CA, Merino MJ, Duray PH. Langerhans cell histiocytosis of the female genital tract. Cancer 1991; 67:1650-60

4. Komp DM, Perry MC. Introduction: the histiocytic syndromes. Sem in Oncol 1991;18(1):1-2. 